for these unused follicles become in some instances the source of ovarian cysts, not in the human female only, but in the individual species throughout the subkingdom mammalia. It serves as an excellent instance of the application of evolution to pathology. Further evidence regarding the fecundity of the progenitors of the human species is furnished by organs otner than the ovaries.

If I were asked by a student to furnish him with a single character, selected from the arterial system of mammals, which could be relied upon as a distinguishing feature in their anatomy, I should certainly choose the internal mammary and deep epigastric arteries. These remarkable vessels form a double line of communication situated on each side of the median line of the abdomen, and serve to connect the subclavian and iliac systems. The parallel offered by two main arterial stems coursing along the ventral aspect of the trunk seems to correspond so closely with the two main stems of the primitive aorta that a morphological explanation of this character seemed irresistible. Prolonged medication and continued observation directed to this question have at length served to convince me that these arteries have some relation with the original disposition of the mammary glands. In man and many quadrumana among the higher Eutheria, and in Sirenia (manatee and dugong) among the lower, the mammæ are situated on the thorax. In the cow, mare, ass, and the like the mammæ occupy an inguinal position. The insectivurous Eutheria, as in so many other characters, hold an intermediate place in this respect, for the teats extend from the pectoral to the abdominal region. In the bats the mammse may occupy, as in Pteropus, the axillæ; this is also the case in Galeopithecus; whilst in some lemurs these glands are placed on the arms. These lastmentioned situations are altogether exceptional; the most

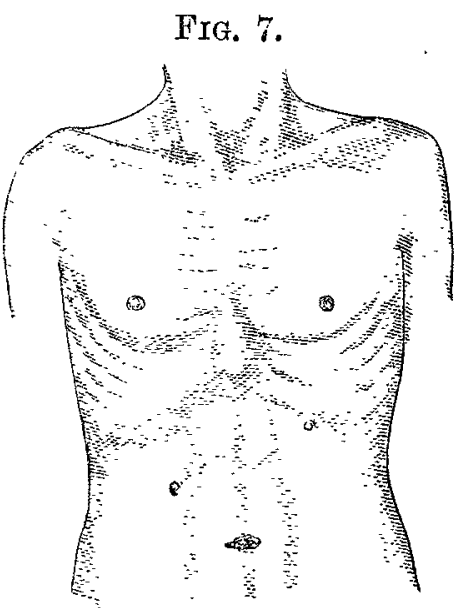

common regions are the pectoral, abdominal, and inguinal. These facts are suggestive of a primitive disposition of the mammary glands along the whole length of the ventral aspect of the trunk. If it be probable that this remarkable disposition of arteries is in any way related to the primitive arrangement of these glands, it would necessarily follow that in cases where the suppressed mammæreappeared as supernumerary organs they ought most frequently to occur in relation with these vessels. This is exactly whathappens. A supernumerary nipple situated on Supernumerary nipples and the abdominal wall of a boy. mammæ are by no means rare, for one observer, Dr. J. Mitchell Bruce, in a careful and valuable paper, ${ }^{10}$ has considered sixty-five cases which came under his observation in three years. This observer informs us that out of 207 men examined in succession $9 \cdot 11$ per cent. presented a supernumerary nipple, and of 104 women 4.807 per cent. In the majority of cases the additional nipple was single, and without exception situated on the front of the trunk below and within the ordinary nipple, and more frequently on the left than on the right side. In more than one instance the anterior abdominal wall was the seat of the abnormality (Fig. 7). Until the appearance of Professor Leichtenstern's oft-quoted paper ${ }^{11}$ supernumerary mammæ were believed to be extremely rare, and it is to this writer that the credit is due of exposing the fallacy. I am unaware of any observer who has personally examined sixty-five and eleven additional cases, except Dr. Mitchell Bruce; Leichtenstern's total was made up of thirteen cases noticed by himself and ninety-two recorded by others. These records clearly show that supernumerary nipples in nearly all cases follow closely the line of the internal mammary and deep epigastric arteries. The occurrence of nipples in male mammals is capable of easy explanation. Darwin was of this opinion: "If we suppose that during a former prolonged period male animals aided the females in nursing their offspring, and that afterwards from some cause (as from the production of a smaller number

10 Journal of Anatomy and Physiology, vol, xiii., p. 425 11 Virchow's Archiv, Bd. Ixxiii. of young) the males ceased to give this aid, disuse of the organs during maturity would lead to their becoming inactive." 12 This view is very plausible and possible, but it is equally probable that, as every mammal at one period of embryonic life is hermaphroditic, the mammæ persist as remnants of that condition; in the same way the functional parovarian in the female represents the efferent ducts of the male gland. The fact that supernumerary mammæ occur twice as frequently in the male as in the female is to be accounted for on the principle of correlation. The female mammæ are functional, and require more blood-supply; this leads to dwarfing of the adjoining glands. The contrary of this pertains in the male. Our knowledge of accessory nipples and glands has been considerably increased since Darwin considered the matter, for, having regard to the very rare and in some instances questionable cases of supernumerary mammæ on the thigh and back, he thought that they weakened the probability of reversion. This did not prevent him ending the discussion in this way: "On the whole, we may well doubt if additional mammæ would ever have been developed in both sexes of mankind had not his early progenitors been providec with more than a single pair." No one can examine the evidence since accumulated without agreeing with this view; hence accessory mammæ must be regarded as atavistic structures in a true sense, and their occurrence is not confined to men, for tiey are not infrequently seen in other mammals, especially cows. The very valuable inquiry conducted by Dr. Champneys, "On the Development, of Mammary Functions by the skin of Lying-in Women," adds a new interest to the matter, for it seems to prove that supernumerary mammæ without nipples may lie hidden under the skin of the axilla, and become active when stimulated by the increased function of the normal mammæ at the termination of pregnancy. Thus, the only conclusion one can arrive at from these facts is that the suppression of ova in foetal ovaries and the very frequent occurrence of supernumerary mammæe and nipples are indicative of an ancestry from forms which not only produced a greater number of offspring, but in whom the males assisted in giving suck to the young.

It is impossible to reflect upon the preceding facts without feeling convinced of the truth of Bacon's remark: "No natural phenomenon can be studied in itself alone, but to be understood must be considered as it stands connected with all nature."

\section{DISEASE IN THE PUNJAB.}

\section{BY SIR JOSEPH FAYRER, M.D., F.R.S., K.C.S.I.}

Is the annual report on the sanitary administration of that part of Northern India included in the Government of the Punjab for 1885, there are facts recorded which it may be interesting to notice.

The population, according to the last census, is $17,514,978$. The deaths from all causes among these were as follows:-

\begin{tabular}{|c|c|c|c|}
\hline Cholera ... & $\cdots$ & 1,936 & ...... \\
\hline Small-pox & .. & 7,575 & $\ldots \ldots$ \\
\hline Fevers $\ldots$ & $\ldots$ & 346,763 & ...... \\
\hline Bowel compl & aints... & 17,711 & $\ldots \ldots$ \\
\hline Injuries ... & $\ldots \quad \ldots$ & 127,606 & $\ldots \ldots$ \\
\hline All causes & $\ldots$ & 507,140 & ....... \\
\hline
\end{tabular}

This return shows how relatively small a part cholera plays during some years in the mortality of the population, but how very grave and important a death cause is found in climatic fevers - a subject which stands much in need of further investigation.

There are two items among the death causes which are of special interesst, and therefore worthy of attention. Under the head of injuries, which gives 127,606 deaths, there are recorded 852 from snake-bite, 146 from hydrophobia, and 17 from wild beasts - the latter item being small indeed compared with the same returns from other parts of India. The deaths from snake-bite are doubtlesss due to Naja tripudians, or the cobra ; Bungarus cœruleus, or krait; and Echis carinata, or small (carpet) viper; and must, one supposes, be considered as inevitable, albeit it is difficult not to consider them as among those deaths which should be regarded as preventable. The hydrophobia cases, which

\footnotetext{
12 Descent of Man. $\quad 13$ Med.-Chir. Trans., vol. Ixix., p. 419
} 
seem to be on the increase, certainly suggest a similar idea ; and also that here would be an excellent opportunity of testing Pasteur's method of treatment-a suggestion which may perchance be deemed not unworthy of adoption by some of our medical officers in the Punjab.

The following details are taken from the report cited; one of the last, it is to be feared, which will be drawn up by Brigade-Surgeon Bellew, C.S.I., whose retirement deprives India of one of her most distinguished sanitary officers :-

"The total deaths registered under the head of "snakebite' were 852 , against 900 in the previous year. In the following districts the number of deaths due to snakebite was larger than in the rest of the districts in the province: Lahore, 67 ; Mooltan, 61; Gujranwala, 58; Jhelum, 51; Muzaffargarb, 49; Kangra, 48; Thaug, 45 ; Montgomery, 42 ; Karnal, 41 . It appears from the returns for the previous years that in these districts deaths from snake-bite are always more numerous than in the other parts of the province.

"The deaths from 'hydrophobia' have of late years very considerably increased, as will be seen from the subjoined table:-

\begin{tabular}{rrrrr|rrrrr}
1885 & $\ldots$ & $\ldots$ & $\ldots$ & 146 & 1881 & $\ldots$ & $\ldots$ & $\ldots$ & 139 \\
1884 & $\ldots$ & $\ldots$ & $\ldots$ & 158 & 1880 & $\ldots$ & $\ldots$ & $\ldots$ & 107 \\
1883 & $\ldots$ & $\ldots$ & $\ldots$ & 117 & 1879 & $\ldots$ & $\ldots$ & $\ldots$ & 69
\end{tabular}

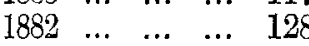

Of the 146 deaths registered during the year under review, 20 occurred in Hushiarpur, 19 in Lahore, 18 in Amritsar, 8 in Mooltan, 7 in each of the districts of Hissar, Ludhiana, Gurdaspur, Montgomery, and Sialkot.

"Five deaths were caused by scorpion sting-viz, 4 in Peshawar and 1 in Mooltan.

"The number of persons killed by wild beasts was as follows:-Carried away by wolves, 3 ; by jackals, 7 ; torn by a leopard, 1 ; by boar, 1 ; by bears, 3 ; killed by croeodiles, 2 . "There are comparatively few tigers in this part of India.

"The deaths registered under the head of "other causes" were 127,604 . Of this number 27,390 were due to chest diseases."

The above shows what an ample field exists for the study of disease in India, and what large opportunities our young medical officers may enjoy of prosecuting their studies in pathology, epiłemiology, and hygiene in all its branches. The subject of fevers especially needs elucidation, and should be studied in a spirit of independence as regards preconceived notions of fever etiology.

Wimpole-street, W

\section{SOME CONSIDERATIONS IN REGARD THE CAUSATION OF SEX.}

BY A. J. WALL, M.D. LOND., H.M. INDIAN ARIYY.

(Concluded from page 203 .)

IN the cases of the fathers and mothers that have been taken it will be observed that each has been treated without reference to the other. The influence of the age of the mother has been considered without regarding the age of the father, and vice versâ. But though this is so, yet, as these were families whose parents married under the ordinary conditions and rules of society, it is clear that a very large proportion of the fathers were a few years older than the mother, and therefore these families must have a preponderating influence. In fact, in these statistics the age of the father was on the average $6^{\circ} 6$ years greater than that of the mother in the whole 1200 families. But if we take the proportions obtained from all these families and contrast them with those we shall obtain by selecting families in which wide differences existed between the ages of the fathers and mothers, we shall then be in a position to see what results are due to these great differences of age.

There are in these tables 111 families in which the father was considerably younger than the mother, the differences being from nine montbs to ten years. In these families there were 546 children, 297 males and 249 females, or $119 \cdot 2$ males to 100 females, being a great excess of males over the mean proportion of $107 \cdot 4$ to 100 . If we divide these births into periods accorling to the age of the mothers we obtain the following results:--In the period of immaturity only two children were born, one of each sex, showing that when the father is younger than the morher, the mother as a rule marries somewhat late in life. In the period from twentytwo to twenty-eight years there were 86 births, 39 males and 47 females, or only 82.9 males to 100 females, against 98.3 males to 100 females, which was the proportion for the whole of the families, showing again how incapable the immature male is of imprinting his sex on the offspring when the female is at her prime. From the twenty-eighth to the thirty-sixth year inclusive of the mother, 179 males

Chant 3. Ages of Mothers.

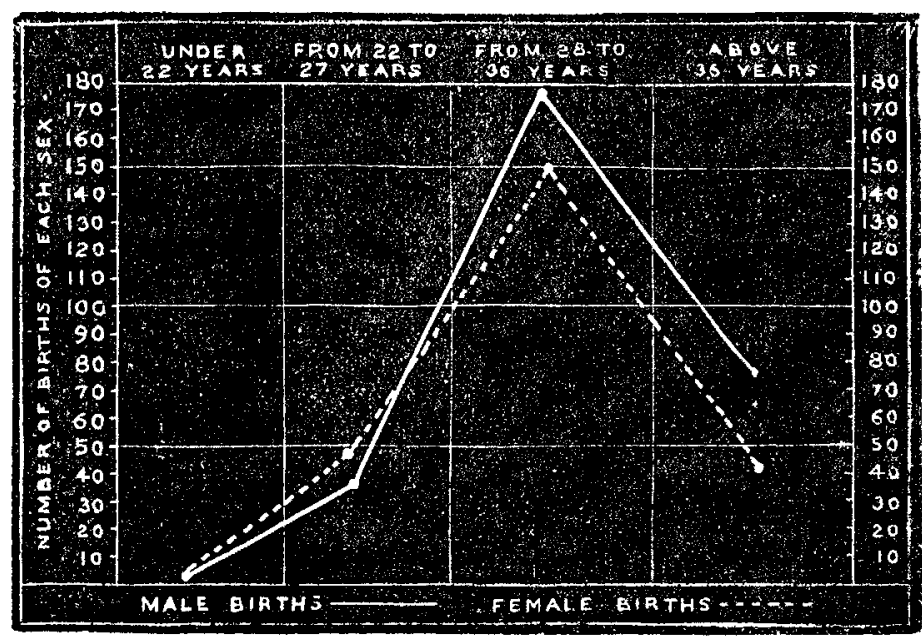

showng the number of male and temale viruhs at diforeno periods of the agrs of the mothers in families in which the father was younger than the mother.

were born to 156 females, or 114.7 males to 100 females, or an excess of male births over the 111.6 males to 100 femules occurring in all families taken together; whereas in the last period of decline of the power of the mother there were 78 males to ouly 45 females, or 1733 males to 100 females, an enormous excess of males over the proportinn obtained for this period at all ages of 114.2 males to 100 females. Chart 3 shows those varying proportions.

Now let us contrast this with a series of families as widely different as possible-that is, where the father is much older than the motber. In 111 fertile families in the :e tables the

CHART 4.

A, es of Mothers.

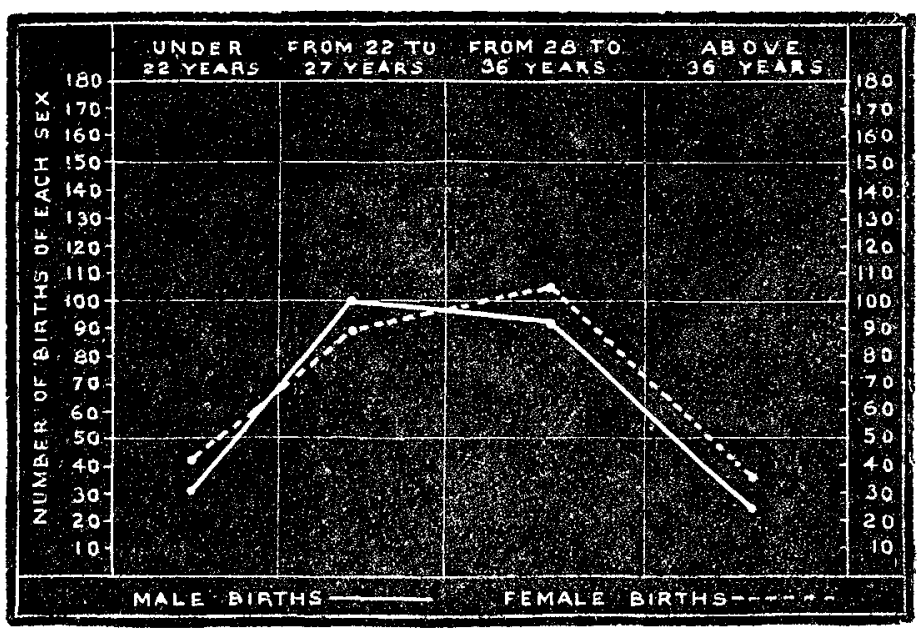

Showing the numbor of male and female births at different periuds of the ages of the mothers in families in which the father was more than fifteen years older than the mother.

father was older than the mother by more than fifteen years, the excess varying from fifteen yeurs to forty-nine years. In these families there were 519 children, 255 being males and 264 being females, or only 965 males to 100 temales, being actually an excess of females at all the ages of the mother taken together. During the period of immaturity of the mother there were 34 males born to 39 females, or 87 males to 100 females, or an excess of females. In the period from twenty-two to twenty-seven years 100 males wer born to 91 females, or 109.8 males to 100 females, or an 